clinical value and to have a record of all the malignant conditions that have been reported, at some time, to respond to one or other agent. For good measure, a separate list of 382 references, mostly from 1956-I 960 , on clinical chemotherapy is included at the end of the book, and there is a useful guide to these same references. Unfortunately, this book leaves much to be desired. Much of it is badly written, and there is a great deal of unnecessary repetition, though, having regard to the depressing nature of the subject, and the very little headway that has been made in recent years in spite of the enormous amount of effort and money that have been devoted to it, one may perhaps forgive the frequency with which the authors end their contributions with apologia and hopes for better things to come. There is no uniformity in the nomenclature of chemical agents used in different articles and this may be a minor source of confusion. Some of the figures are poorly annotated and the graph on p. 56 is quite meaningless to the reviewer. The most disappointing feature of the book is that the reader is left with a half-digested mass of assorted information from which he can glean no underlying rationale. This is not so much the fault of the authors and editors as a reflection of the unpromising condition of this side of cancer research. For the present this book, for all its shortcomings, does fill a gap.

\section{A Clinical Prospect of the Cancer Problem}

D. W. SMITHERS, M.D., F.R.C.P., F.F.R. Introductory Volume: Neoplastic Diseases at Various Sites. Pp. $232+\mathrm{xv}$, illustrated. Edinburgh and London: E. \& S. Livingstone. 1960. 37s. $6 d$.

This is the introductory volume to a series of monographs, each of which is intended to cover the problems of cancer at a particular site, in considerable detail. The result is a remarkably stimulating book which is essential reading, in its own right, for all those interested in cancer, even though they have no intention of reading the later volumes.

Professor Smithers' knowledge of the problem is profound, and every possible aspect is discussed in a lively and provocative manner. He believes that neoplasia is a natural sequel of excessive tissue regeneration; which is often associated with injury or with isolation away from controlling environmental influences. Such a process would be expected to be found sometimes with hormonal abnormalities, and would occur inevitably more often with advancing age. At first, such a philosophy may appear to be excessively gloomy, but it does allow a realistic view to be taken of the prospects of controlling cancer.

Due emphasis is laid upon the wide spectrum of disease processes that is covered by the term 'cancer', which vary from a vague borderland, overlapping benign overgrowth, to the completely autonomous, highly malignant tumour. The logical management of each type of neoplasm requires a clear understanding of its growth potential and probable behaviour, and the chapters discussing the principles of treatment summarise the present position in a masterly manner. Each method of management is logically related to the tumour type.

Emphasis is rightly laid upon the limitations of the available chemotherapeutic methods of cancer therapy. Unfortunately, there is no way of curbing the misplaced enthusiasm of poorly informed clinicians, whose childhood dreams of magic have remained unaltered with the passage of time. Most chemotherapeutic agents can produce serious side-effects, without necessarily bermefiting the patient, and their use may cause unnecessafy delay before the institution of more effective, orthod methods of treatment.

One of the most thought provoking chapters is that 6 n 'Quackery and Education'. Various aspects of the problem are discussed in detail and it is humbling realize that the main fact encouraging quackery is a lack of confidence in the orthodox medical practitiongr.

As regards the early detection of cancer, the auth. clearly expects very little from special cancer detection centres, but he would like to see a better understanding $f$ the cancer problem amongst the medical profession $\frac{1}{\mathrm{j}^{n}}$ general. This book will certainly help towards thes; and everyone interested in cancer should make the tirge to read it. No one will find the task onerous.

An occasional minor misprint can be found. $\overrightarrow{\Theta_{n}}$ page 37 , 'of' has been omitted from the sentents '- precise boundaries this side death'. On page I 45 , Fig. 34 is referred to in the text as showing a rising deffifh rate in men, and a falling rate in women, while Fig. $\$_{5}$ on the following page is said to demonstrate a downwafaet trend in both sexes. Presumably these illustrations have been interchanged. 6-mercaptopurine is cluded as a folic acid antagnosist on page 212 , and. it seems inconsistent to refer to Myleran (busulphan) a $\overrightarrow{\mathrm{d}}$ in the following paragraph to chlorambucil (Leukeraศ. These trifling adverse criticisms are all that the reviews can offer, after repeated detailed readings of the text which were prompted by the fascinating material.

The author's extremely attractive general style and stimulating method of presentation make this exciting book. The reviewer would like to record that this is one of the few medical volumes that he has for suitable and enjoyable for reading in bed. It cao ge recommended enthusiastically without any reservations, to all those interested in the subject. Professor Smi must be congratulated most sincerely on his superb The general production is first class, and the prioge extremely reasonable.

\section{Vertebrate Biochemistry in Preparation for Medicine}

M. W. NeIL, PH.D., F.R.I.C. Pp. xii $+342+$ inde illustrated. London: Pitman Medical. I96I. 4\%

This book has been written mainly for preclinical medical students, though the author clearly hopes that the subject matter will appeal to its audience for own sake and not merely as an adjunct to clinical studies.

The first section contains a valuable description $\overrightarrow{B f}$ modern biochemical techniques. The second edition. discusses enzyme action and the next section is introduction to bio-energetics. The rest of the book deals with digestion, metabolism and blood chemistro, together with a final section on kidney function and
acid-base balance.

The book has been kept to a modest size, though the cost of deliberately neglecting several topics, suda as vitamins and hormones. This seems a great pity ard could perhaps be rectified in the next edition. The book could still be kept down to its present reasonable siof by omitting some of the detail in the section of metabolism.

The book is to be recommended warmly. It illustrates vividly the fact that the modern biochemist must chemist, biologist and physicist at one and the sange time.

Erratum.- The title of a book reviewed in our February issue, 1962, should have been: 'Proceedings of the Fourti International Congress on Clinical Chemistry', Edinburgh, August I4 to I9, I960. London: Butterworth. I96r. 3 